\title{
TO ACCESS THE SAFETY AND SUCCESS OF TRANSRADIAL CORONARY ANGIOGRAPHY IN A TERTIARY CARE HOSPITAL
}

\author{
SHER BAHADAR KHAN ${ }^{1}$, ALAM ZEB $^{2}$, TAJ MUHAMMAD KHAN ${ }^{2}$, KHURSHAID AHMAD \\ NAZIA LIAQAT ${ }^{4}$, ADNAN MAHMOOD GUL', MUHAMMAD HAFIZULLAH ${ }^{1}$ \\ 1.Department of Cardiology, PGMI, Lady Reading Hospital Peshawar. \\ 2.Department of Physiology Saidu Medical College Swat. \\ 3. Medical Superintendent, Saidu Group of Teaching Hospital, Swat. \\ 4.Department of Gynae/Obs, Saidu Group of Teaching Hospital, Swat.
}

\section{ABSTRACT}

OBJECTIVE: To determine the safety and success of transradial coronary angiography and angioplasty in a tertiary care hospital.

METHODS: The feasibility and safety of routine transradial coronary angiography was assessed prospectively in 591 patients from March 2011 to March 2013 at Cath lab of cardiology department Lady Reading Hospital Peshawar. All patients with normal Allen's test were included in study. Patients having abnormal or modified Allen's test, on haemodialysis or had abnormal serum creatinine level were excluded from the study. If the rightradial approach was used in all cases. The main outcome measures were success rate and complications of transradial coronary angiography. The catheter selection was a $6 \mathrm{FJL} 3.5$ for right coronary artery and 6FJR 4 catheter for left coronary artery. In 354(60 percent) cases, coronary angiography was performed by using $6 \mathrm{~F} \mathrm{JR} 4$ for both coronary arteries.

RESULTS: The mean age was $55 \pm 10.08$ years with $437(74 \%)$ males and $154(26 \%)$ females. A total of 591 coronary angiographies were perform though trans-radial route in the study period. Overall procedure success rate was $95 \%$ (561 patients) for transradial coronary angiography, with mean procedure time of $21.25 \pm 5.25$ minutes ,mean fluoroscopy time of $6 \pm 3.15$ minutes, and $90 \%$ of patients were discharged on the same day. Only 2 patients had mild forearm haematoma, pain and spasm of radial artery occlusion occurred in $20(3.38 \%)$ study patients. A symptomatic radial occlusion in $8(1.35 \%)$. The reason for failure of transradial procedure included failed radial artery puncture $(n=6)$, radial artery loop $(n=2)$, tortuous subclavian artery $(n=3)$, failed catheterization of coronary arteries in 5 patients $(2.53 \%)$ and severe radial artery spasm in $20(3.38 \%)$.

CONCLUSION: Trans-radial artery cannulation is a safe and successful route for performance of coronary procedures. It can be used as an acceptable alternate to transfemoral.

\section{INTRODUCTION}

Common femoral artery (CFA), was the key site for angiography because of its large diameter so large catheters were used. The CFA approach for coronary interventions could be complicated by serious vascular access site complications including haematomas accompanied by significant blood loss, arterial pseudoaneurysm and arteriovenous fistulas. Bleeding from vascular access site is by far the most feared complication especially with use of anticoagulation and platelet Glycoprotein IIb/IIIa inhibitors. The overall incidence of major bleeding was $3.9 \%$ in the GRACE 1 (global registry of acute coronary events) registry, out of that vascular access site bleeding occurred in $23.8 \%$ and retroperitoneal bleeding in $6 \%$ of patients undergoing angioplasty in the setting of acute coronary syndrome from transfemoral approach. The in hospital mortality was significantly higher in patients with major bleeding than in those without major bleeding (18.6\% vs $5.1 \%$ ). In 1989 Campeau first reported the result of transradial angiography (TRCAG) with $5 \mathrm{~F}$ catheter in 100 patients with a success rate of $88 \%$ without any access site complications ${ }^{2}$. Later the work by Kiemeneijetal ${ }^{3}$ in angioplasty through transradial route ${ }^{3}$ has taken the cardiology into the realm of minimal invasive percutaneous interventions which attracted the interventionist worldwide. In comparison to transfemoral route, 
major vascular access site complications are minimized from radial artery approach, even with concomitant use of high doses of anticoagulation and Glycoprotein IIb/IIIa platelet inhibitors ${ }^{4-5}$.

In spite of the potential benefits of this approach, coronary angiography continues to be performed via the femoral artery in $85 \%$ to $90 \%$ of cases. Although there have been significant improvements in catheter dimensions, vascular complications are still frequent with the femoral route, particularly in obese patients, aortoiliac disease, or where potent anticoagulants or thrombolytics are used. Such complications result in prolonged hospital stay and increased need for transfusion; they also prevent early ambulation.

This study was designed to determine whether the radial approach could be used routinely for coronary angiography in our patients. The primary objectives were to assess the feasibility of transradial angiography for selective catheterization of the coronary arteries, and to determine the complication rate and procedure duration. Data was collected for future comparison with the femoral route in terms of radiation exposure, procedure duration, and complications.

\section{METHODOLOGY}

This prospective study was carried out over a 24month period of 591 patients from March 2011 to March 2013, in cardiology department Lady Reading Hospital Peshawar, a major tertiary referral center of province of Khyber Pukhtunkhawa. All patients had a functional palmar arch as assessed by an Allen's test ${ }^{6}$. Contraindications included a negative Allen's test, chronic renal failure requiring regular hemodialysis.

Informed consent was obtained in all cases. With the arm abducted 30 degrees to the body in the supineposition, the hand was hyperextended. Local anesthesia consisted of 1 to $2 \mathrm{~mL}$ of $2 \%$ lignocaine injected subcutaneously, just enough to produce a wheal over the $\operatorname{skin}^{7}$. A puncture was made with a short pricking needle. A $6 \mathrm{~F}$ sheath was used in most patients (Terromatransradial sheath). After introduction of the sheath, a spasmolytic consisting of nitroglycerin $200 \mu \mathrm{g}$ were injected intraarterially. Left and right Judkins diagnostic catheters were used for the left and right coronary arteries.

In $60 \%$ of cases $6 \mathrm{~F}$ JR 3.5 cather used to cannulate both left and right coronary arteries. The sheath was removed immediately, allowing a brisk back flow of blood to expel any clots. Hemostasis was achieved by applying a firm pressure over radial artery followed by applying atornique. The tourniquet was removed after 1 hour. Patients were ambulated immediately, and discharged the same day whenever possible.

Radial access time was measured from injection of lignocain to introduction of 0.018 inch guide wire. Procedure time was measured from the point of time patient was ready for procedure until procedure is completed. Fluoroscopy time was defined as the total time of fluoroscopy use during the coronary angiography. Complications were considered as significant if there was a large forearm haematoma with haemoglobin drop of $2 \mathrm{mg} / \mathrm{dl}$, requirement of blood transfusion because of blood loss at vascular access or surgical intervention because of acute compartment syndrome and forearm ischaemia. Allen's test is a valid clinical screening test for assessment of hand circulation and to prevent ischaemic complication of the hand ${ }^{8}$.

The Allen's test was performed by asking the patient to clench the fist for 1 minute while both radial and ulnar arteries were compressed with the examiner's fingers. The palm of the hand blanched. Then compression of ulnar artery was released; the normal colour of palm returned within 10 seconds, if there was adequate collateral circulation. A positive test was reported when there was abnormality in the capillary filling of the fingers in 10 seconds. The modified Allen's test was performed similarly except radial artery was released instead of ulnar artery and normal blush of hand was noted. All procedures were supervised by interventionist with significant experience in transradial interventions.

The following data was collected in a database 
throughout the study period: successful radial puncture and cannulation, selective catheterization of each vessel and type of catheter used (as well as success or failure), procedure duration, screening time, complications, and patient comfort (comfortable/painful). The collected data was entered and analyzed by the Statistical Package for Social Sciences version 15.0 Software (SPSS Inc., Chicago, Illinois). Discrete variables were expressed as percentage frequencies and continuous variables as mean \pm standard deviation.

\section{RESULTS}

The mean age was $55 \pm 10.08$ years with $437(74 \%)$ males and $154(26 \%)$ females. A total of 591 coronary angiographies from the trans-radial route in the study period. Overall procedural success rate was $95 \%$ (561 patients) for trans radial coronary angiography, with mean procedure time of $21.25 \pm$ 5.25 minutes, mean fluoroscopy time of $6 \pm 3.15$ minutes, and $90 \%$ of patients were discharged on the same day. Only 2 patients had mild fore arm haematoma and asymptomatic radial artery occlusion occurred in $8(1.35 \%)$ study patients. Overall procedural un success rate was 5\% (30 patients) for transradial coronary angiography, and converted to femoral route. The reason for failure of transradial procedure included failed radial artery puncture $(n=6)$, radial artery $\operatorname{loop}(n=2)$,tortuous subclavian artery $(n=3)$, failed catheterization of coronary arteries in 5 patients $(2.53 \%)$ and severe radial artery spasm in 20(3.38\%). Shown in table 1 .

\section{Table -1}

\begin{tabular}{|l|c|l|c|}
\hline During procedure & Complications & After procedure & Complications \\
\hline $\begin{array}{l}\text { Haemotoma at site of } \\
\text { puncture }\end{array}$ & 02 & Puncture failure & 06 \\
\hline Occlusion & 08 & Radial loop & 02 \\
\hline & & Tortuous & 03 \\
\hline & & Catharization failure & \\
\hline
\end{tabular}

Table 2: Demographic and clinical characteristics in 591 patients.

\begin{tabular}{|l|l|l|}
\hline Variables & No. of patients & $\%$ \\
\hline Mean age (years) & $54 \pm 10.08$ & \\
\hline Male & 437 & 74 \\
\hline Female & 154 & 26 \\
\hline Indication for angiogram & & \\
\hline Positive stress test & 291 & 49 \\
\hline Unstable angina & 153 & 26 \\
\hline Stable angina & 99 & 17 \\
\hline Post infarction angina & 48 & 08 \\
\hline
\end{tabular}

Table 3. Puncture Site Complications in 591 Patients

\begin{tabular}{|l|l|l|}
\hline Complications & No. of patients & $\%$ \\
\hline Asymptomatic radial thrombosis & 21 & 3.50 \\
\hline Hand ischemia (transient) & 2 & 0.30 \\
\hline Minor fore arm hematoma & 2 & 0.30 \\
\hline Pain or spasm & 20 & 3.38 \\
\hline Vascular surgery & 2 & 0.30 \\
\hline
\end{tabular}

\section{DISCUSSION}

In our study, overall procedural success rate was $95 \%$ (561 patients) for trans radial coronary angiography, in comparison to it a study by Kiemeneijetal in 1993, the failure to complete the procedure from radial artery approach has been relatively high and related to radial artery spasm, radial loops, subclavian artery tortuosity and dilated aortic root $^{3}$.Transradial approach has a learning curve period and the failure rate is especially high during this period. With experience, failure rate could be reduced from $10 \%$ to $1 \%$ after 1000 cases $^{9}$. The failure or cross over rate of radial access site was $5.9 \%$ in the metaanalysis by Jolly et al, ${ }^{10}$ compared to $1.4 \%$ in the femoral group. A dichotomous trend was noted in cross over or failure rate in the studies performed in the early era of radial access and the recent era (2011-2013).

In our study only 2 patients had mild forearm haematoma and asymptomatic radial artery occlusion occurred in $8(1.35 \%)$ study patients. The reason for failure of transradial procedure included failed radial artery puncture $(n=6)$,radial artery loop $(n=2)$, tortuous subclavian artery $(n=3)$, failed catheterization of coronary arteries in 5 patients $(2.53 \%)$ and severe radial artery spasm in 
$20(3.38 \%)$. This lower rate of complications is also clear from international data which has demonstrated that the most successful coronary percutaneous intervention can be complicated by vascular access site complications in as much as 2$8 \%$ of cases performed from transfemoral route ${ }^{4.11}$. The findings of access study also clearly demonstrated reduction of major access site complications from radial compared to femoral and brachial approaches ( $0 \%$ vs $2.3 \%$ vs $2 \% \%$ respectively)". In a recent meta- analysis of 22 randomized controlled trials by Sanjit S Jolly et al, ${ }^{10}$ radial access reduced major bleeding by $73 \%$ compared to femoral access $(0.05 \%$ vs $2.3 \%)$, OR 0.27 [ $95 \%$ CI $0.16-0.45], p<.001)$. Asymptomatic radial artery occlusion occurs in 3-5\% of patients in different studies ${ }^{12}$. Asymptomatic, in hospital radial artery occlusion occurred in $1.4 \%$ of our study population. In our study, no post discharge followups were done, so the lesser number of occluded radial artery could be an under-estimate. Majority of occluded radials are known to recanalize overtime ${ }^{13}$.

In our study mean procedure time of $21.25 \pm 5.25$ minutes, mean fluoroscopy time of $6 \pm 3.15$ minutes, and $90 \%$ of patients were discharged on the same day. In comparison to our study, in the carafe study ${ }^{14}$, the procedural duration from the radial approach was $12.4 \pm 5.8 \mathrm{~min}$ and fluoroscopy time was $3.8 \pm 2.2$ min for coronary angiography. The procedural time in the transradial group (40.2 $\mathrm{min}$ ) was longer than the transfemoral approach $(37.0 \mathrm{~min})$ in the study by Bruecket $\mathrm{al}^{15}$, but it was recognized that if sheath removal time of transfemoral procedure had been included, the procedure duration would have been similar $^{15}$. This has been demonstrated that radial experts have shorter procedure time compared to non-radial experts ${ }^{10}$. The limitation of our study was the absence of a comparative femoral group, because I selected all the cases I have performed myself, and we preffer femoral route in selective cases like CTO and complex bifurcations lesions. Another limitation was lack of followup for identification of radial artery occlusion or any other complication.

\section{CONCLUSIONS}

The radial artery approach is found to be very safe with high degree of success and low vascular access site complications for coronary diagnostic and interventional procedures in local population.

\section{ACKNOWLEDGMENT}

I acknowledge the efforts of Dr. Alam Zeb, for his statistical assistance.

\section{REFERENCES}

1. Moscucci M, Fox KA, Cannon CP, Klein W, LópezSendón J, Montalescot G, et al. Predictors of major bleeding in acute coronary syndromes: the Global Registry of Acute Coronary Events (GRACE).EurHeartJ2003;24:1815-23.

2. Campeau L. Percutaneous radial artery approach for coronary angioplasty. Catheter Cardiovasc Diagn 1989;16:3-7.

3. Kiemeneij F, Laarman GJ. Percutaneous transradial artery approach for coronary stent implantation. Catheter Cardiovasc Diagn 1993;30:173-8.

4. Choussat R, BlackA, Bossi I, Fajadet J, Marco J. Vascular complications and clinical outcomes after coronary angioplasty with platelet $\mathrm{IIb} / \mathrm{IIa}$ receptor blockade. Comparison of transradial vs transfemoral arterial access. Eur Heart J 2000; 21: 662-7.

5. Cruden NL, Teh CH, Starkey IR, Newby DE. Reduced vascular complications and length of stay with transradial rescue angioplasty for acute myocardial infarction. Catheter Cardiovasc Interv2007;70:670-5.

6. McConnell EA. Performing Allen's test. Nursing 1997; 27:26.

7. Joly LM, Spaulding C, Monchi M, Ali OS, Weber S, Benhamou D. Topical lidocaine-prilocaine cream (EMLA) versus local infiltration anesthesia for radial artery cannulation. AnesthAnalg 1998;87:403-6.

8. Kohonen M, Teerenhovi O, Terho T, Laurikka J, Tarkka $M$. Is the Allen test re enough? EurJ Cardiothorac Surg2007;32:902-5.

9. Louvard Y, Pezzano M, Scheers L, Koukoui F, Marien C, BenaimR,etal. Coronary angiography by a radial approach: feasibility, learning curve .One operator's experience. Arch Mal Coeur Vaiss 1998; 91:209-15

10.Jolly SS, Amlani S, Hamon M, Yusuf S, Mehta SR. Radial versus femoral access for coronary angiography or intervention and the impact on major bleeding and ischemic events: A systematic review and meta-analysis of randomized trials. Am Heart J 2009; 157: 132-40.

11.Kiemeneij F, Laarman GJ, Odekerken D, Slagboom T, Vander Wieken R. A randomized comparison of percutaneous transluminal coronary angioplasty by the radial, brachial and femoral approaches: the ACESS study. J Am CollCardiol 1997; 29: 1269-75

12.Stella PR, Odekerken D, Kemeneij F, Laarman GJ, Slagboom. Incidence and outcome of radial artery occlusion following transradial coronary angioplasty. 
Catheter Cardiovasc Diagn 1997;40:156-8.

13.Caputo RP, Simons A, Giambartolomei A, Grant W, Fedele K, Abraham S, et al. Safety and efficacy of repeat transradial access for cardiac catheterization procedures. Catheter Cardiovasc Interv 2001; 54: 188-90.

14.Louvard Y, Lefèvre T, Allain A, Morice M. Coronary angiography through the radial or the femoral approach: The CARAFE study. Catheter Cardiovasc Interv 2001; 52: 181-7.

15.Brueck M, Bandorski D, Kramer W, Wieczorek M, Höltgen R, Tillmanns H. A randomized comparison of transradial versus transfemoral approach for coronary angiography and angioplasty. JACC Cardiovasc Interv. 2009;2:1047-5.

FOR CORRESPONDENCE:

Dr. Sher Bahadar Khan, Consultant Cardiologist, Cardiology

Department, PGMI,

Lady Reading Hospital, Peshawar.

Email:docyousafzai@yahoo.com

Cell \#:0333 9487717 